\title{
Retraction
}

\section{Retracted: Slope Stability Analysis Using Limit Equilibrium Method in Nonlinear Criterion}

\section{The Scientific World Journal}

Received 31 December 2014; Accepted 31 December 2014

Copyright (C) 2015 The Scientific World Journal. This is an open access article distributed under the Creative Commons Attribution License, which permits unrestricted use, distribution, and reproduction in any medium, provided the original work is properly cited.

The paper titled "Slope Stability Analysis Using Limit Equilibrium Method in Nonlinear Criterion" [1], published in The Scientific World Journal, has been retracted upon the authors' request as it was found to include erroneous data. Its findings and conclusion cannot be relied on.

\section{References}

[1] H. Lin, W. Zhong, W. Xiong, and W. Tang, "Slope stability analysis using limit equilibrium method in nonlinear criterion," The Scientific World Journal, vol. 2014, Article ID 206062, 7 pages, 2014. 

Nonlinear Criterion

\author{
Hang Lin, ${ }^{1,2,3}$ Wenwen Zhong, ${ }^{2}$ Wei Xiong, ${ }^{2}$ and Wenyu Tang ${ }^{2}$ \\ ${ }^{1}$ Changjiang River Scientific Research Institute, Wuhan, Hubei 430010, China \\ ${ }^{2}$ School of Resources and Safety Engineering, Central South University, Changsha, Hunan 410083, China \\ ${ }^{3}$ Key Laboratory of Transportation Tunnel Engineering, Ministry of Education, Southwest Jiaotong University, \\ Chengdu, Sichuan 610031, China
}

Correspondence should be addressed to Hang Lin; linhangabc@126.com

Received 7 April 2014; Revised 10 July 2014; Accepted 11 July 2014; Published 23 July 2014

Academic Editor: Paolo Vannucci

Copyright $\odot 2014$ Hang Lin et al. This is an open access article distributed under the Creative Commons Attribution License, which permits unrestricted use, distribution, and reproduction in any medium, provided the original work is properly cited.

In slope stability analysis, the limit equilibrium method is usually used to calculate the safety factor of slope based on MohrCoulomb criterion. However, Mohr-Coulomb criterion is restricted to the description of rock mass. To overcome its shortcomings, this paper combined Hoek-Brown criterion and limit equilibrium method and proposed an equation for calculating the safety factor of slope with limit equilibrium method in Hoek-Brown criterion through equivalent cohesive strength and the friction angle. Moreover, this paper investigates the impact of Hoek-Brown parameters on the safety factor of slope, which reveals that there is linear relation between equivalent cohesive strength and weakening factor $D$. However, there are nonlinear relations between equivalent cohesive strength and Geological Strength Index (GSI), the uniaxial compressive strength of intact rock $\sigma_{c i}$, and the parameter of intact rock $m_{i}$. There is nonlinear relation between the friction angle and all Hoek-Brown parameters. With the increase of $D$, the safety factor of slope $F$ decreases linearly; with the increase of GSI, $F$ increases nonlinearly; when $\sigma_{c i}$ is relatively small, the relation between $F$ and $\sigma_{c i}$ is nonlinear, but when $\sigma_{c i}$ is relatively large, the relation is linear; with the increase of $m_{i}, F$ decreases first and then increases.

\section{Introduction}

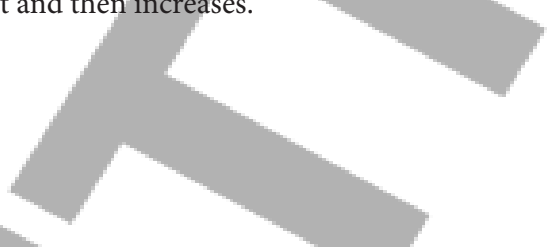

The analysis of slope stability is an important aspect of research in disaster reduction engineering. In the analysis of slope stability, the primary task is to calculate the safety factor of the slope [1-5]. Because the analysis of slope stability is statically indeterminate, the factor of safety cannot be obtained directly from the static equilibrium condition. In order to avoid the complex relation between stress and strain and the difficulty in transforming the statically indeterminate problem into the statically determinate problem, reasonable approximations for the analysis of slope stability are required. Thus the problem can be solved in statically determinate form with limit equilibrium method (LEM) [6-8]. This method is at the cost of the rigor but has little impact on the precision. It is applied widely in engineering projects with many distinctive advantages; for example, it simplifies the analytical calculation and shortens the computing time. The fundamental feature of limit equilibrium method is only considering the static equilibrium condition and Mohr-Coulomb criterion; that is, the solution to the problem is the analysis of the equilibrium of forces at the moment of the failure of soil mass. However, there is a restriction of Mohr-Coulomb criterion to the description of rock mass; for example, it fails to explain the impact of high stress areas but only reflects the feature of linear failure in rock mass $[9,10]$. To overcome the above shortcomings, based on large amount of rock tests and related materials, Hoek and Brown proposed HoekBrown criterion which can reflect intrinsic characteristics including the rock strength [10-12], the number of rock joints, and the impact of stress state on rock strength as well as the feature of nonlinear failure. The criterion matches characteristics of deformation and failure well [13-16] which won the high reputation and wide application in geological 


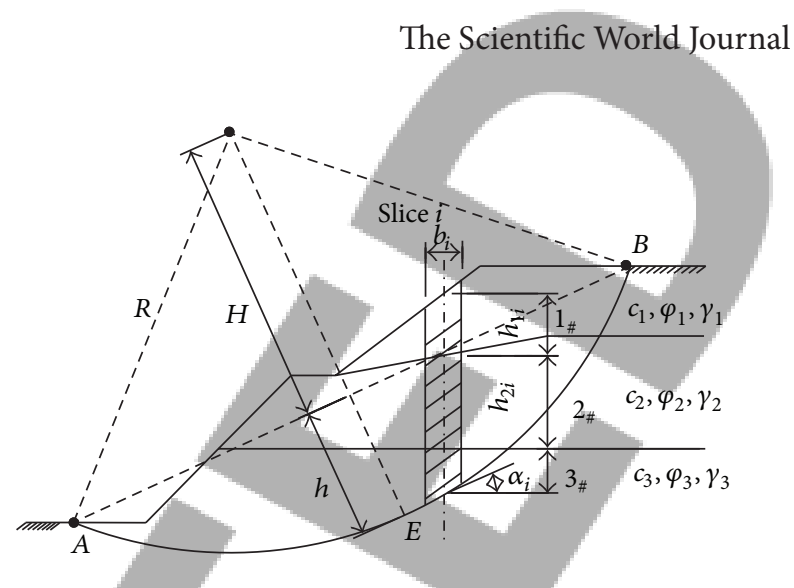

engineering. Zhang et al. [17] proposed a three-dimensional (3D) version of the generalized Hoek-Brown strength criterion. Halakatevakis and Sofianos [9] investigated HoekBrown criterion analytically through an extended plane of weakness theory and validated it with experimental evidence on physical specimens. Besides, some scholars applied numerical analytical methods to slope stability on the basis of Hoek-Brown criterion. While numerical methods consume long time to calculate the safety factor of the slope [18], for instance, when taking the CPU time required by each of the models on the same computer into consideration, limit equilibrium method ran considerably faster, taking about 2 minutes per run compared with 30 minutes and 7 hours using the coarse (about 2000 elements) and fine grids (about 7000 elements), respectively, by numerical calculation method. Though the traditional method for the safety factor, limit equilibrium method, owns the advantage of simplicity, it fails to combine Hoek-Brown criterion. Taking all the above factors into account, this paper proposed an equation for the safety factor with limit equilibrium method in Hoek-Brown criterion through theoretical deduction. Moreover, this paper investigates the impact of Hoek-Brown parameters on the safety factor of slope.

\section{Definition of Safety Factor}

So far, there are three types of safety factors [2, 3, 19]: (1) the strength reserve factor of safety obtained through lowering the strength of rock and soil mass; (2) the overload reserve factor of safety obtained through increasing the exterior load; (3) the driving force overloading reserve factor, a design value of landslide thrust calculated through amplifying the driving force along the slope while keeping the corresponding resisting force constant. The limit equilibrium method mainly adopts the concept of the strength reserve factor.

In 1955, Bishop proposed the modified Bishop method [20], an effective and simple method to analyze circular slip surfaces. In this method, the safety factor $F_{s 1}$ is defined as the potential sliding along a failure surface. After reducing the shear strength index by $F_{s 1}$ times, that is, $c^{0} / F_{s 1}$ and $\tan \phi^{0} / F_{s 1}$, the rock and soil mass along the failure surface are in a state of limiting equilibrium; that is,

$$
\tau=c^{c r}+\sigma \tan \phi^{c r},
$$

where $\tau$ is the shear strength and $\sigma$ is the normal stress at failure surfaces; $c^{c r}=c^{0} / F_{s 1} ; \tan \phi^{c r}=\tan \phi^{0} / F_{s 1}$, where $c^{0}$ and $\phi^{0}$ are the cohesive strength and the friction angle, respectively, in original state; $c^{c r}$ and $\phi^{c r}$ are the cohesive strength and the friction angle, respectively, in the limit equilibrium state of the slope.

The mentioned method that takes the reserve of strength index to define the factor of safety has clear physical meanings. The factor of safety is the ratio of resisting to deriving forces acting at the slope along the failure surface. This type of safety factor is only reducing the resisting forces while keeping deriving forces constant. Comparatively, the definition of safety factor with strength reserve matches the practical engineering projects more perfectly, because
FIGURE 1: Theoretical model for deducing the safety factor of slope.

frequently they are external factors that contribute to failures of slopes and the decrease of strength of rock and soil mass. Thus, this definition has been widely accepted by engineers around the world with the examination of practical projects for many years.

\section{Hoek-Brown Equivalent Limit Equilibrium Method}

The modified Bishop method is applied widely in practical engineering projects [21-23]. As a limit equilibrium method, this method is not confined to the shape of failure surface and possesses relatively high precision. The result with this method is very close to the one with the strict slice method. Therefore, this paper adopts the modified Bishop method to calculate the factor of safety. The modified Bishop method sets three hypothetical conditions: (1) the actual tangential force at the failure surface is the part that the shear strength works; (2) the vertical shear strength between slices is ignored; (3) the yield of soil mass matches the MohrCoulomb criterion. The calculation model for safety factor of slope is illustrated in Figure 1. Through deduction, the factor of safety can be expressed as

$$
F_{s}=\frac{\sum m_{a i}\left[c_{i} b_{i}+\left(W_{i}-u_{i} b_{i}\right) \tan \phi_{i}\right]}{\sum W_{i} \sin \alpha_{i}}
$$

where

$$
m_{a i}=\frac{1}{\cos \alpha_{i}+\left(\tan \phi_{i} \sin \alpha_{i} / F_{s}\right)},
$$

where $F_{s}$ is the safety factor of slope and $c_{i}$ and $\phi_{i}$ are the effective cohesive strength and the friction angle of soil layer. If the slope is homogeneous, both the cohesive strength and the friction angle are constant; $u_{i}$ is the pore water pressure loading at the failure surface of the soil slice $i ; b_{i}$ is the width of soil slice; $\alpha_{i}$ is the inclination of the bottom of soil slice from the horizontal; $W_{i}$ is the gravity of soil slice $i, W_{i}=$ $\gamma_{1} b_{i} h_{1 i}+\gamma_{2} b_{i} h_{2 i}+\cdots+\gamma_{j} b_{i} h_{j i}+\cdots+\gamma_{k} b_{i} h_{k i} ; k$ is the number of soil layer where the failure surface is; $\gamma_{j}$ is the bulk density of the soil at the number $j$ layer; $h_{j i}$ is the height of slice $i$ in the number $j$ soil layer. 
On the basis of (1), if the relation between Hoek-Brown strength parameters and Mohr-Coulomb strength parameters can be set up, substituting parameters gives the safety factor of slope through the modified Bishop method in HoekBrown criterion. Therefore, the first step is to deduce the relation between Hoek-Brown criterion and Mohr-Coulomb criterion.

Hoek-Brown criterion is expressed as [10-12]

$$
\sigma_{1}^{\prime}=\sigma_{3}^{\prime}+\left(m_{b} \sigma_{c i} \sigma_{3}^{\prime}+s \sigma_{c i}^{2}\right)^{a}
$$

where $\sigma_{1}^{\prime}$ is the effective maximum principle stress when the rock mass is destroyed; $\sigma_{3}^{\prime}$ is the effective minimum principle stress loaded at the rock mass; $\sigma_{c i}$ is the uniaxial compressive strength of intact rock; $m_{b}$ is the constant of rock mass and is related to $m_{i}$ of intact rock; $s$ and $a$ are the coefficient depending on features of rock mass. All of these parameters can be described with a function of the Geological Strength Index (GSI).

Specific functions are as follows [12, 17]:

$$
\begin{aligned}
m_{b} & =m_{i} \cdot \exp \left[\frac{(\mathrm{GSI}-100)}{(28-14 D)}\right], \\
s & =\exp \left[\frac{(\mathrm{GSI}-100)}{(9-3 D)}\right], \\
a & =\frac{1}{2}+\frac{e^{-\mathrm{GSI} / 15}-e^{-20 / 3}}{6},
\end{aligned}
$$

where $D$ is the weakening factor of rock which is related to the excavation way and the disturbing degree. The value of $D$ is in the range of $0 \sim 1$, where 0 indicates the undisturbed state.

Equation (4) is differentiated to obtain

$$
\frac{d \sigma_{1}^{\prime}}{d \sigma_{3}^{\prime}}=1+a m_{b} \sigma_{c i}\left(m_{b} \sigma_{3}^{\prime} \sigma_{c i}+s \sigma_{c i}^{2}\right)^{a-1} .
$$

Based on (6), the shear stress and the normal stress are expressed with the principle stress [10]:

$$
\begin{gathered}
\tau=\frac{\left(\sigma_{1}^{\prime}-\sigma_{3}^{\prime}\right) \sqrt{d \sigma_{1}^{\prime} / d \sigma_{3}^{\prime}}}{\left(d \sigma_{1}^{\prime} / d \sigma_{3}^{\prime}+1\right)}, \\
\sigma_{n}^{\prime}=\frac{\sigma_{1}^{\prime}+\sigma_{3}^{\prime}}{2}-\frac{\left(\sigma_{1}^{\prime}-\sigma_{3}^{\prime}\right)}{2} \cdot \frac{\left(d \sigma_{1}^{\prime} / d \sigma_{3}^{\prime}\right)-1}{\left(d \sigma_{1}^{\prime} / d \sigma_{3}^{\prime}\right)+1} .
\end{gathered}
$$

Since Mohr-Coulomb failure criterion is still widely used in geotechnical engineering analysis, it is necessary to determine equivalent angles of friction and cohesive strengths for each rock mass and stress range. In Mohr-Coulomb criterion, $\tan \phi=d \tau / d \sigma_{n}, c=\tau-\sigma_{n} \tan \phi$. By fitting an average linear relationship to the curve generated by solving (4) for a range of minor principal stress values, as illustrated in Figure 2, the

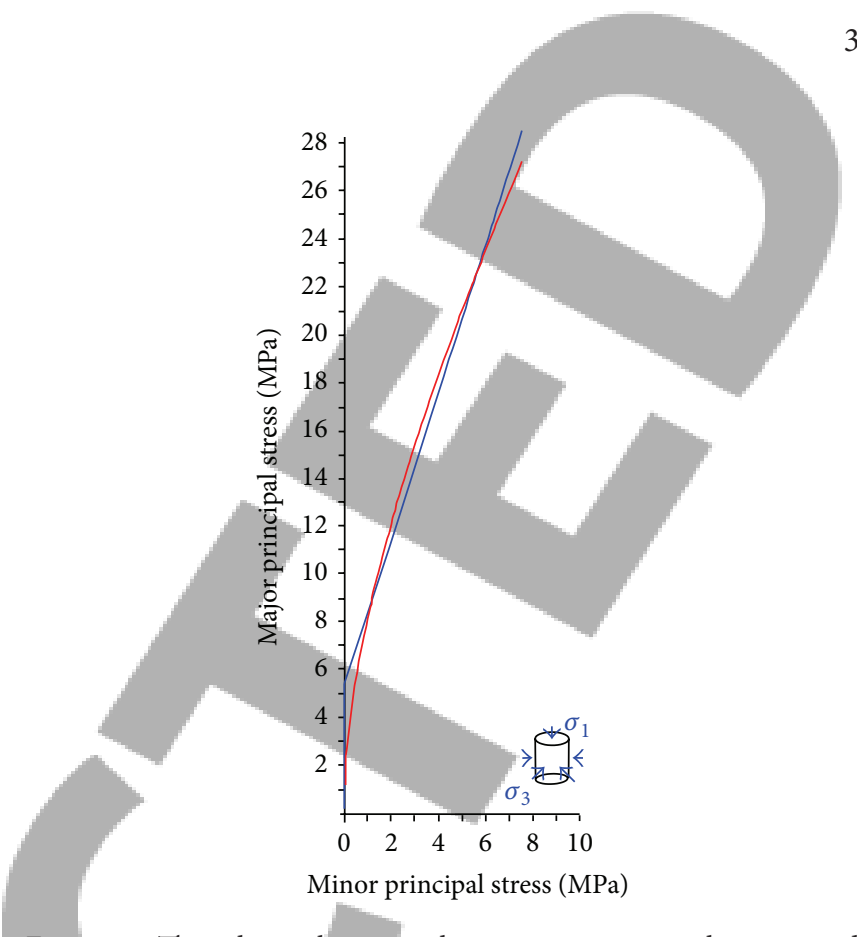

FIGURE 2: The relation between the maximum principle stress and the minimum principle stress in Hoek-Brown criterion and MohrCoulomb criterion.

equivalent angle of internal friction and the cohesive strength can be obtained as [12]

$$
\begin{gathered}
\phi=\arcsin \left(\frac{f_{b} f_{c}}{2 f_{a}+f_{b} f_{c}}\right), \\
c=\frac{\sigma_{c i} f_{c}\left[s(1+2 a)+(1-a) m_{b} \sigma_{3 n}\right]}{f_{a} \sqrt{1+f_{b} f_{c} / f_{a}}},
\end{gathered}
$$

where $f_{a}=(1+a)(2+a) ; f_{b}=6 a m_{b} ; f_{c}=(s+$ $\left.m_{b} \sigma_{3 n}^{\prime}\right)^{a-1} ; \sigma_{3 n}^{\prime}=\sigma_{3 \max }^{\prime} / \sigma_{c i} ; \sigma_{3 \max }^{\prime}$ is the upper limit of confining stress over which the relationship between the Hoek-Brown and the Mohr-Coulomb criteria is considered, has to be determined for each individual case [12]. In the studies of slopes using Bishop's circular failure analysis for a wide range of slope geometries and rock mass properties, $\sigma_{3 \max }^{\prime}=0.72\left(\sigma_{c m} / \gamma H\right)^{-0.91} ; \gamma$ is the bulk density of rock mass; $H$ is the height of slope; $\sigma_{c m}$ indicates the strength of rock mass:

$$
\sigma_{c m}=\sigma_{c i} \frac{\left[m_{b}+4 s-a\left(m_{b}-8 s\right)\left(m_{b} / 4+s\right)^{a-1}\right]}{2(1+a)(2+a)} .
$$

The fitting process involves balancing the areas above and below the Mohr-Coulomb plot. Transferring Figure 2 into the strength envelope diagram Figure 3 shows that the Hoek-Brown envelope diagram is a curve, while the MohrCoulomb envelope diagram is a straight line [12]. Figure 3 is divided into three parts and marked as regions 1,2 , and 3 , respectively. When the normal stress is in region 1 or region 3, the equivalent Mohr-Coulomb strength parameter will overestimate the shear strength of rock mass. When most of normal stress at the bottom of failure surface concentrates in region 1 or region 3 , the factor of safety calculated with 


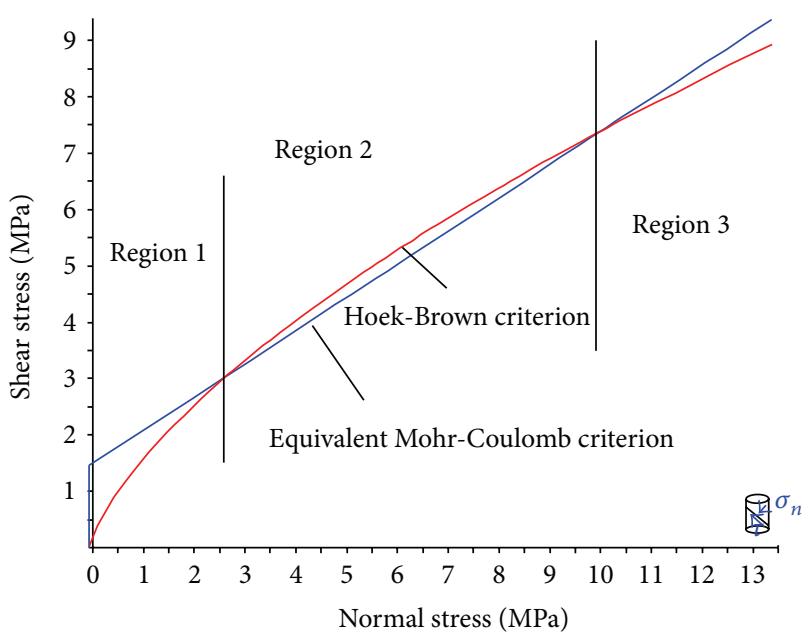

FIGURE 3: The Hoek-Brown strength envelope diagram and equivalent Mohr-Coulomb strength envelope diagram.

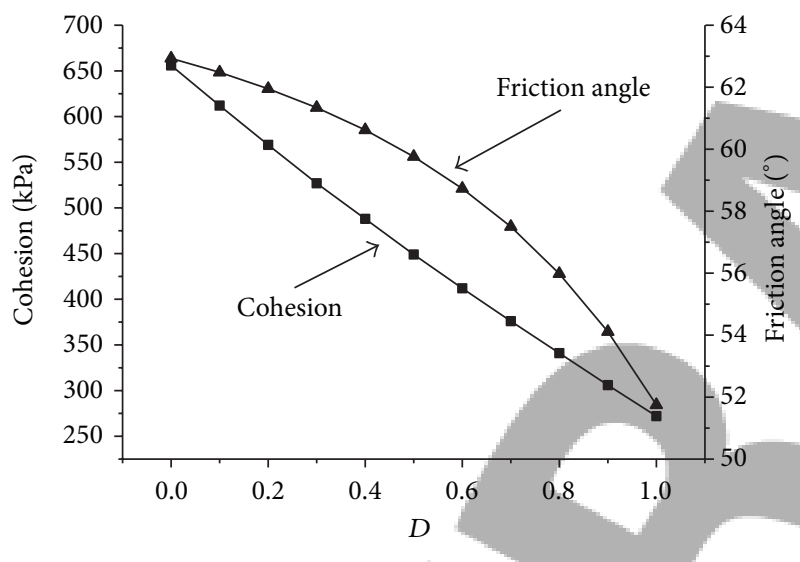

FIGURE 4: The relation between $D$ and the cohesive strength/angle of internal friction.

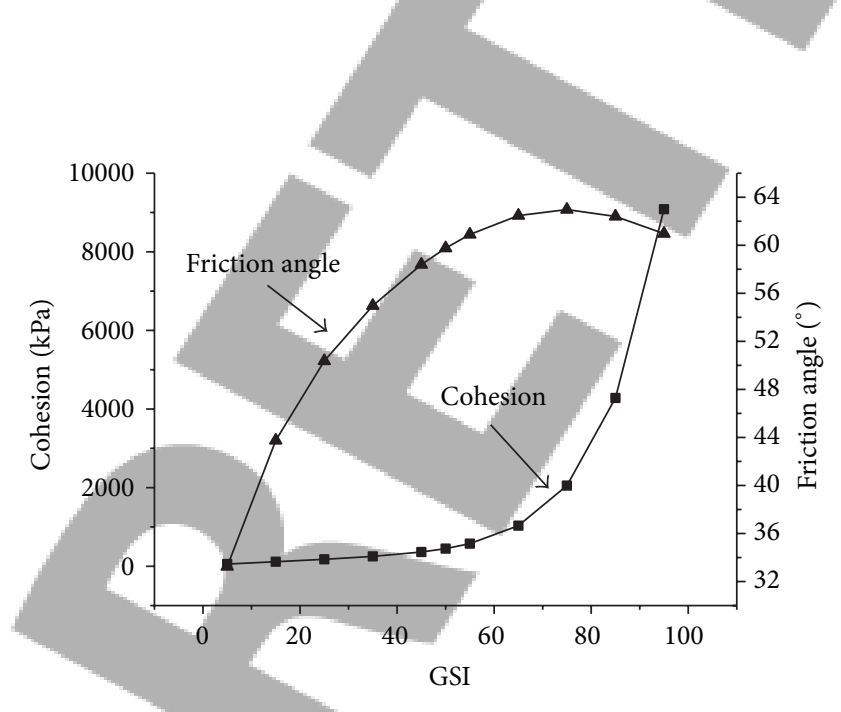

FIGURE 5: The relation between GSI and the cohesive strength/angle of internal friction.

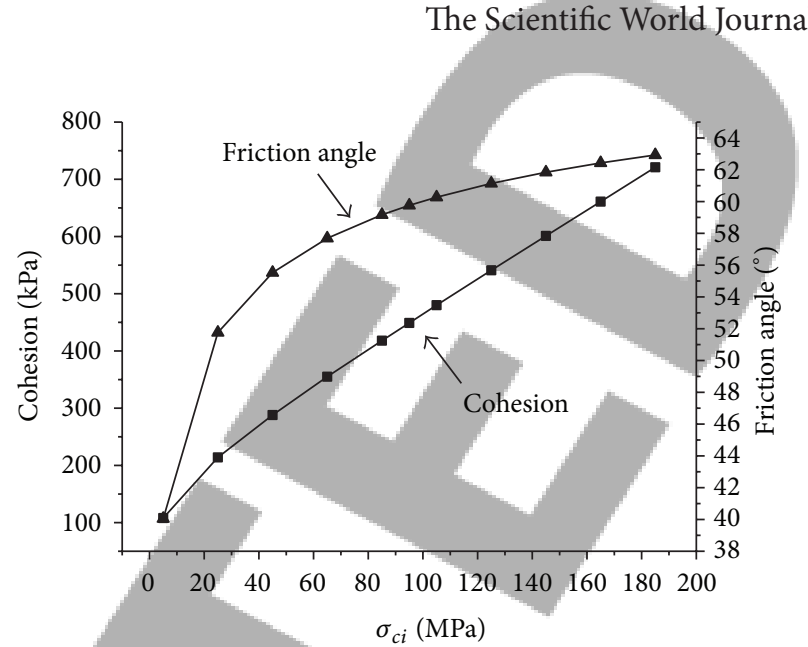

FIGURE 6: The relation between $\sigma_{c i}$ and the cohesive strength/angle of internal friction.

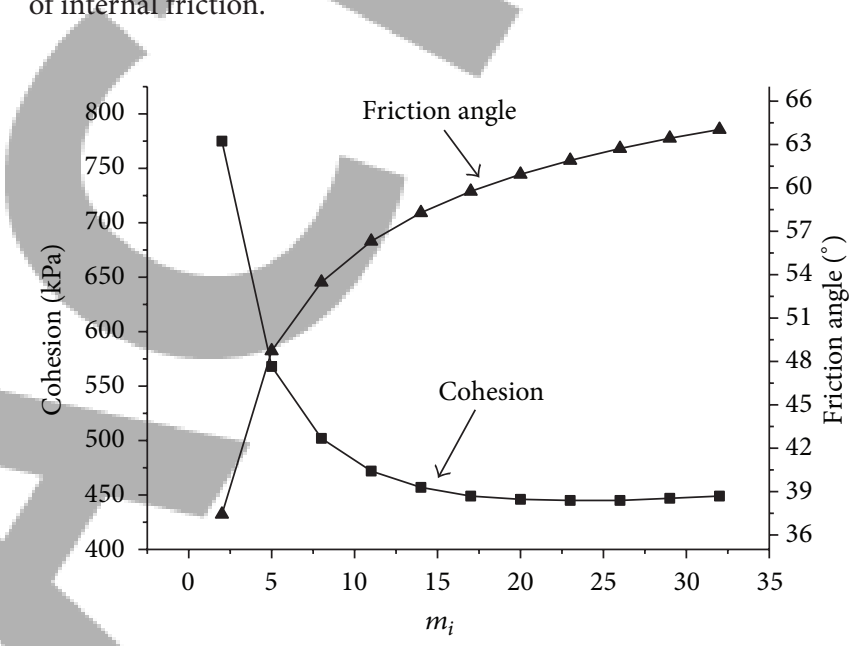

FIGURE 7: The relation between $m_{i}$ and the cohesive strength/angle of internal friction.

equivalent Mohr-Coulomb strength parameters may slightly be insecure. Through the above deduction, substituting (8) and (9) into (2) gives the safety factor of slope calculated by the modified Bishop method in Hoek-Brown criterion.

\section{Parametric Analysis}

The height of a slope is $20 \mathrm{~m}$ and the inclination is $1: 0.5$. For the convenience of discussion, the homogenous model of slope is set up. Basic calculating parameters are bulk density $\gamma=25.0 \mathrm{kN} / \mathrm{m}^{3}, m_{i}=17, D=0.5$, GSI $=50$, and $\sigma_{c i}=$ $95.0 \mathrm{MPa}$.

Changing parameters, respectively, $m_{i}=2 \sim 32, D=0 \sim$ 1 , GSI $=5 \sim 95$, and $\sigma_{c i}=5 \sim 185 \mathrm{MPa}$, in (8) and (9), gives the corresponding Mohr-Coulomb parameters, that is, the cohesive strength $c$ and the friction angle $\phi$. Figures 4, 5, 6 , and 7 present relations between Hoek-Brown parameters, that is, $D, \mathrm{GSI}, \sigma_{c i}$ and $m_{i}$, and the cohesive strength $c$ as well as the friction angle $\phi$. These figures illustrate that the equivalent friction angle and the cohesive strength of rock material decrease gradually with the increase of weakening factor $D$. Furthermore, the relation between the cohesive 


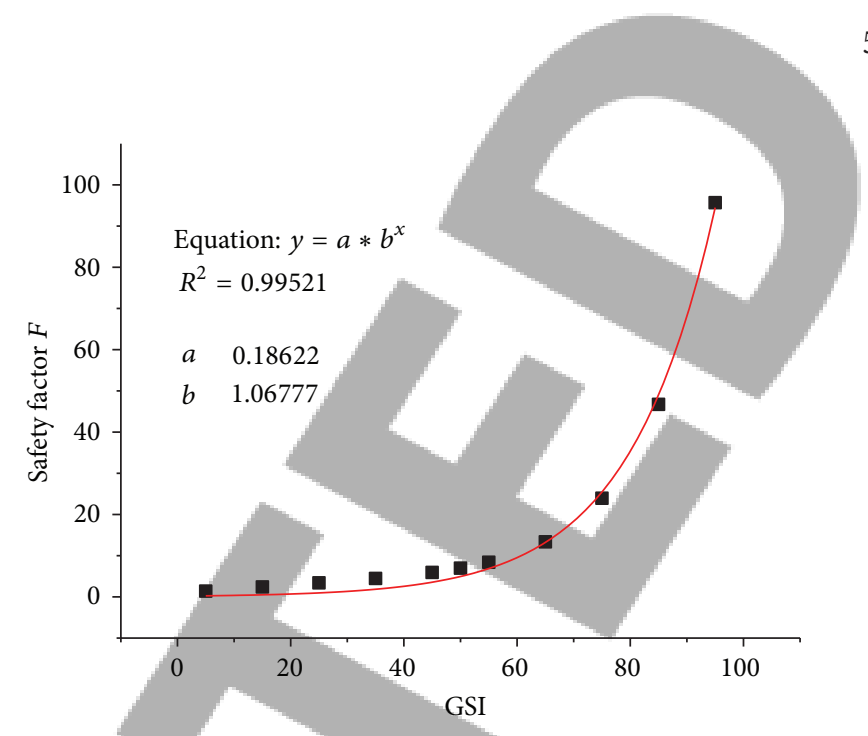

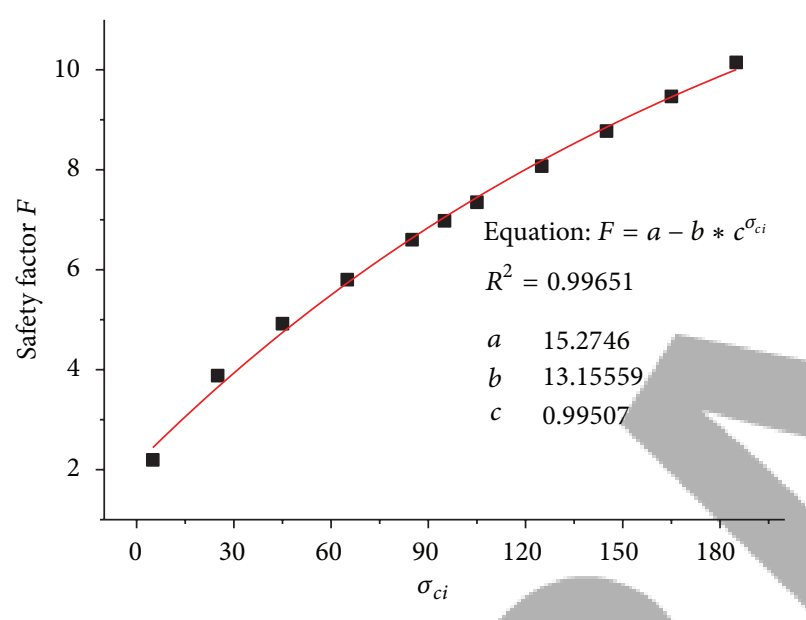

(c) The relation between $\sigma_{c i}$ and $F$ (b) The relation between GSI and $F$

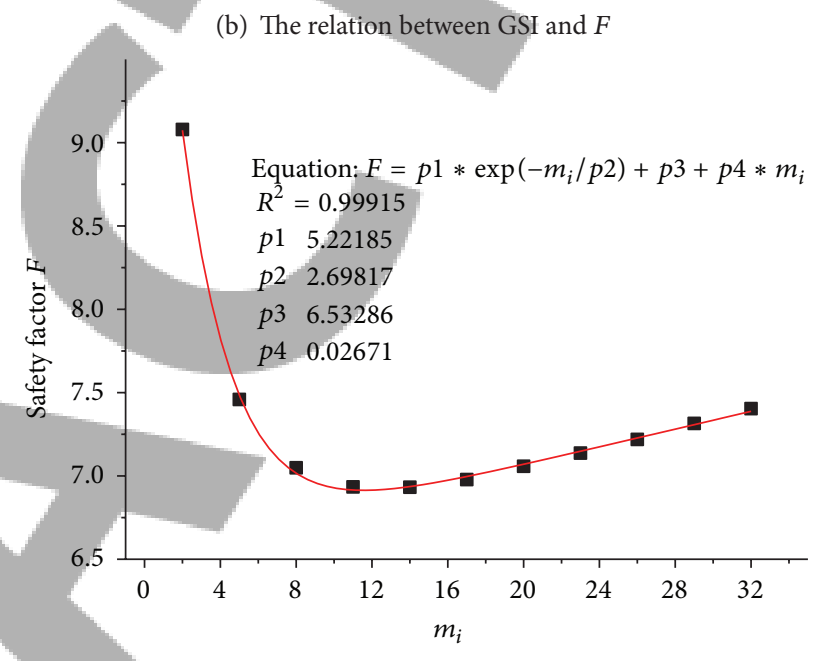

(d) The relation between $m_{i}$ and $F$

FIGURE 8: The relation between the safety factor of slope $F$ and all Hoek-Brown parameters.

strength and $D$ is linear but the relation between the friction angle and $D$ is nonlinear. The relation between GSI and the cohesive strength is nonlinear as well as the friction angle. Moreover, with the increase of GSI, the cohesive strength increases, but the friction angle increases first and then decreases. With the increase of $\sigma_{c i}$, the cohesive strength presents a tendency of linear increase, while the friction angle presents a tendency of nonlinear increase. What is more, the slope of relation curve of the friction angle and $\sigma_{c i}$ decreases gradually as $\sigma_{c i}$ increases, which reveals that the friction angle is very sensitive to the impact of $\sigma_{c i}$ when the value of $\sigma_{c i}$ is relatively small. As $m_{i}$ increases, the cohesive strength shows the nonlinear decreasing characteristic, while the friction angle shows the nonlinear increasing characteristic. That is to say, $m_{i}$ has the opposite impact on the cohesive strength and the friction angle.

Figure 8 displays the relation between the safety factor of slope $F$ and other parameters. It can be concluded from the figure that as for the $D$, the linear characteristic of $F$ decreases with the increase of $D$ and the relation matches the function $F=-4.918 \cdot(D-1.920)$. As for GSI, the nonlinear characteristic of $F$ increases with the increase of GSI and the relation matches the exponential equation $F=$ $0.186 \cdot 1.068^{\mathrm{GSI}}$. When GSI $>60$, the amplitude of increase of $F$ is obviously large which is much higher than $F$ with the change of other parameters. As for $\sigma_{c i}$, when $\sigma_{c i}$ is relatively small, the relation between $F$ and $\sigma_{c i}$ is nonlinear, while it turns out to be linear when $\sigma_{c i}$ is relatively large and it can be fitted with the function $F=15.275-13.156 \cdot 0.995^{\sigma_{c i}}$ with high correlation. As for $m_{i}, F$ decreases first and then increases with the increase of $m_{i}$ which matches the function $F=5.222 \cdot \exp \left(-m_{i} / 2.698\right)+6.533+0.0267 \cdot m_{i}$ well.

\section{Conclusions}

(1) Relations between Hoek-Brown parameters, that is, $D$, GSI, $\sigma_{c i}$ and $m_{i}$, and the cohesive strength as well as the friction angle are set up based on theoretical calculation and the corresponding equivalent cohesive strength and the friction angle with Hoek-Brown parameters. 
(2) The equation for calculating the safety factor of slope with limit equilibrium method in Hoek-Brown criterion is set up through equivalent cohesive strength and the friction angle. This method is applicable with practical value.

(3) There is linear relation between equivalent cohesive strength and weakening factor $D$. However, there are nonlinear relations between equivalent cohesive strength and Geological Strength Index (GSI), the uniaxial compressive strength of intact rock $\sigma_{c i}$, and the parameter of intact rock $m_{i}$. There is nonlinear relation between the friction angle and all HoekBrown parameters.

(4) With the increase of $D$, the safety factor of slope $F$ decreases linearly; with the increase of GSI, $F$ increases nonlinearly; when $\sigma_{c i}$ is relatively small, the relation between $F$ and $\sigma_{c i}$ is nonlinear, but when $\sigma_{c i}$ is relatively large, the relation is linear; with the increase of $m_{i}, F$ decreases first and then increases.

\section{Conflict of Interests}

The authors declare that there is no conflict of interests regarding the publication of this paper.

\section{Acknowledgments}

This paper gets its funding from Project (CKWV2014218/KY) funded by CRSRI Open Research Program; Project (TTE2014-03) supported by Key Laboratory of Transportation Tunnel Engineering, Ministry of Education, Southwest Jiaotong University; and Project (51304240) supported by National Natural Science Foundation of China. The authors wish to acknowledge these supports.

\section{References}

[1] X. P. Zhou and H. Cheng, "Analysis of stability of threedimensional slopes using the rigorous limit equilibrium method," Engineering Geology, vol. 160, pp. 21-33, 2013.

[2] H. Zheng, L. G. Tham, and D. Liu, "On two definitions of the factor of safety commonly used in the finite element slope stability analysis," Computers and Geotechnics, vol. 33, no. 3, pp. 188-195, 2006.

[3] K. Ugai and D. Leshchinsky, "Three-dimensional limit equilibrium and finite element analyses: a comparison of results," Soils and Foundations, vol. 35, no. 4, pp. 1-7, 1995.

[4] H. Lin and P. Cao, "A dimensionless parameter determining slip surfaces in homogeneous slopes," KSCE Journal of Civil Engineering, vol. 18, no. 2, pp. 470-474, 2014.

[5] J. Shen, M. Karakus, and C. Xu, "Chart-based slope stability assessment using the Generalized Hoek-Brown criterion," International Journal of Rock Mechanics and Mining Sciences, vol. 64, pp. 210-219, 2013.

[6] F. Cai and K. Ugai, "Reinforcing mechanism of anchors in slopes: A numerical comparison of results of LEM and FEM," International Journal for Numerical and Analytical Methods in Geomechanics, vol. 27, no. 7, pp. 549-564, 2003.
[7] M. Ataei and S. Bodaghabadi, "Comprehensive analysis of slope stability and determination of stable slopes in the Chador-Malu iron ore mine using numerical and limit equilibrium methods," Journal of China University of Mining and Technology, vol. 18, no. 4, pp. 488-493, 2008.

[8] W. B. Wei, Y. M. Cheng, and L. Li, “Three-dimensional slope failure analysis by the strength reduction and limit equilibrium methods," Computers and Geotechnics, vol. 36, no. 1-2, pp. 7080, 2009.

[9] N. Halakatevakis and A. I. Sofianos, "Correlation of the HoekBrown failure criterion for a sparsely jointed rock mass with an extended plane of weakness theory," International Journal of Rock Mechanics and Mining Sciences, vol. 47, no. 7, pp. 1166-1179, 2010.

[10] E. Hoek, "Estimating Mohr-Coulomb friction and cohesion values from the Hoek-Brown failure criterion," International Journal of Rock Mechanics and Mining Sciences and Geomechanics Abstracts, vol. 27, no. 3, pp. 227-229, 1990.

[11] E. Hoek and E. T. Brown, "Practical estimates of rock mass strength," International Journal of Rock Mechanics and Mining Sciences, vol. 34, no. 8, pp. 1165-1186, 1997.

[12] E. Hoek, C. Carranza-Torres, and B. Corkum, "Hoek-Brown failure criterion-2002 edition," in Proceedings of the 5th North American Rock Mechanics Symposium (NARMS-TAC '02), pp. 267-273, 2002.

[13] T. Benz, R. Schwab, R. A. Kauther, and P. A. Vermeer, "A HoekBrown criterion with intrinsic material strength factorization," International Journal of Rock Mechanics and Mining Sciences, vol. 45, no. 2, pp. 210-222, 2008.

[14] Y. Lee and S. Pietruszczak, "Application of critical plane approach to the prediction of strength anisotropy in transversely isotropic rock masses," International Journal of Rock Mechanics and Mining Sciences, vol. 45, no. 4, pp. 513-523, 2008.

[15] Y. K. Lee, S. Pietruszczak, and B. H. Choi, "Failure criteria for rocks based on smooth approximations to Mohr-Coulomb and Hoek-Brown failure functions," International Journal of Rock Mechanics and Mining Sciences, vol. 56, pp. 146-160, 2012.

[16] A. J. Li, R. S. Merifield, and A. V. Lyamin, "Stability charts for rock slopes based on the Hoek-Brown failure criterion," International Journal of Rock Mechanics and Mining Sciences, vol. 45, no. 5, pp. 689-700, 2008.

[17] Q. Zhang, H. Zhu, and L. Zhang, "Modification of a generalized three-dimensional Hoek-Brown strength criterion," International Journal of Rock Mechanics and Mining Sciences, vol. 59, pp. 80-96, 2013.

[18] H. Lin, W. Xiong, and P. Cao, "Stability of soil nailed slope using strength reduction method," European Journal of Environmental and Civil Engineering, vol. 17, no. 9, pp. 872-885, 2013.

[19] T. Matsui and K. C. San, "Finite element slope stability analysis by shear strength reduction technique," Soils and Foundations, vol. 32, no. 1, pp. 59-70, 1992.

[20] A. W. Bishop, "The use of the slip circle in the stability analysis of slopes," Geotechnique, vol. 5, pp. 7-17, 1955.

[21] L. R. Alejano, A. M. Ferrero, P. Ramírez-Oyanguren, and M. I. Álvarez Fernández, "Comparison of limit-equilibrium, numerical and physical models of wall slope stability," International Journal of Rock Mechanics and Mining Sciences, vol. 48, no. 1, pp. 16-26, 2011. 
[22] J. Jiang and T. Yamagami, "A new back analysis of strength parameters from single slips," Computers and Geotechnics, vol. 35, no. 2, pp. 286-291, 2008.

[23] J. Jiang and T. Yamagami, "Charts for estimating strength parameters from slips in homogeneous slopes," Computers and Geotechnics, vol. 33, no. 6-7, pp. 294-304, 2006.
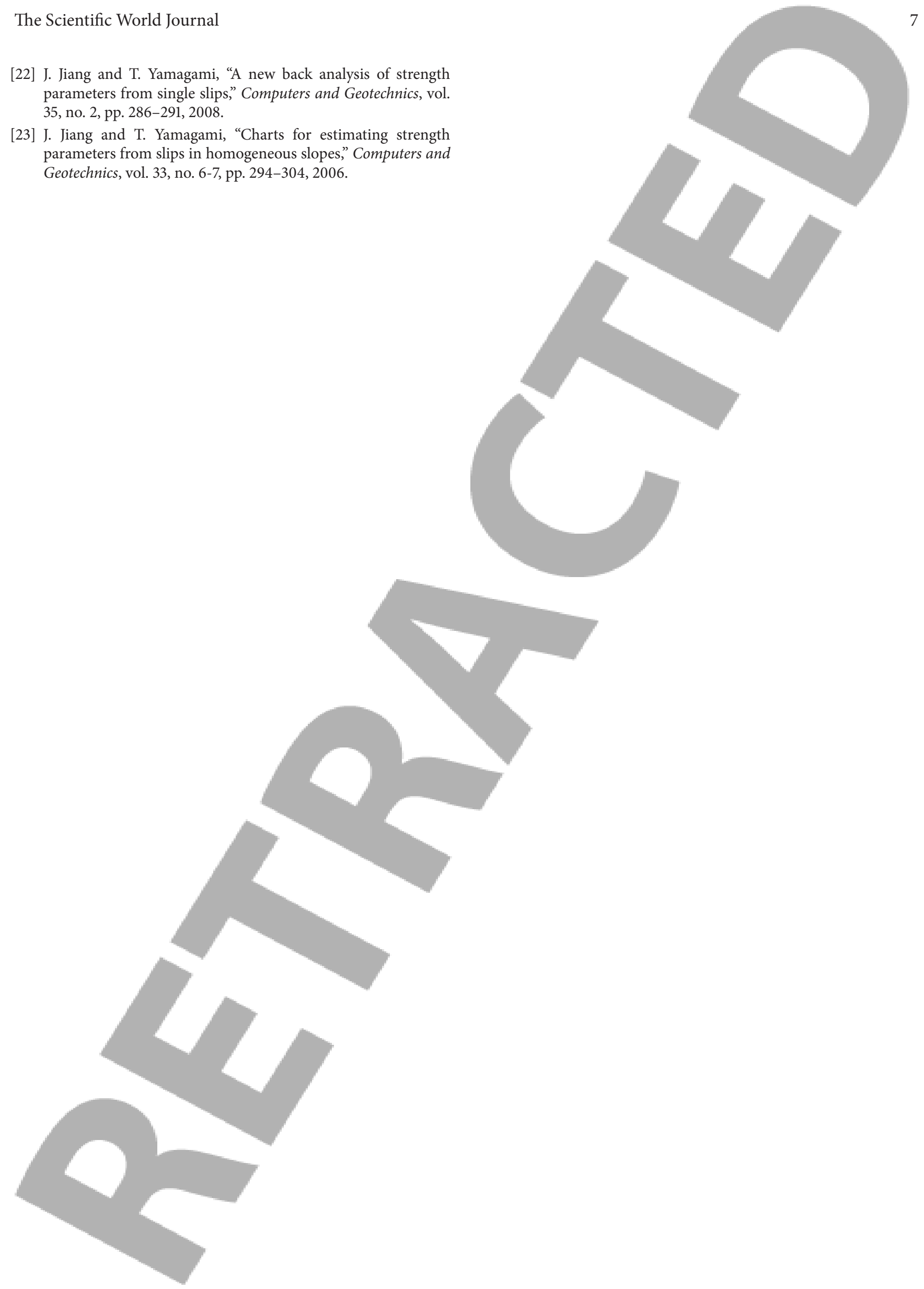